\title{
The Behavior of the Instantaneous Speed Ratio at Merging Area of Traffic Flowing on Federal Highway
}

\author{
Nur Syahirah Husin Basri ${ }^{1}$, Nurul Akmal Mohamed ${ }^{1, *}$, Muhammad Akram Adnan ${ }^{2}, \operatorname{Rab}_{\text {Nawaz }}{ }^{3}$, \\ Nurul Hila Zainuddin ${ }^{1}$, Nurul Farihan Mohamed $^{4}$ \\ ${ }^{1}$ Mathematics Department, Faculty of Science \& Mathematics, Universiti Pendidikan Sultan Idris, 35900 Tanjong Malim, Perak, \\ ${ }^{2}$ Faculty of Civil Engineering, Universiti Teknologi Mara, 40450 Shah Alam, Selangor, Malaysia \\ ${ }^{3}$ Department of Mathematics, COMSATS University Islamabad, Islamabad Campus,Park Road, Islamabad 45550, Pakistan \\ ${ }^{4}$ Kolej GENIUS Insan, Universiti Sains Islam Malaysia, Bandar Baru Nilai, 71800 Nilai, Negeri Sembilan, Malaysia
}

Received January 28, 2021; Revised April 6, 2021; Accepted June 5, 2021

\section{Cite This Paper in the following Citation Styles}

(a): [1] Nur Syahirah Husin Basri, Nurul Akmal Mohamed, Muhammad Akram Adnan, Rab Nawaz, Nurul Hila Zainuddin, Nurul Farihan Mohamed, "The Behavior of the Instantaneous Speed Ratio at Merging Area of Traffic Flowing on Federal Highway," Civil Engineering and Architecture, Vol. 9, No. 4, pp. 1268 - 1276, 2021. DOI: 10.13189/cea.2021.090428.

(b): Nur Syahirah Husin Basri, Nurul Akmal Mohamed, Muhammad Akram Adnan, Rab Nawaz, Nurul Hila Zainuddin, Nurul Farihan Mohamed (2021). The Behavior of the Instantaneous Speed Ratio at Merging Area of Traffic Flowing on Federal Highway. Civil Engineering and Architecture, 9(4), 1268 - 1276. DOI: 10.13189/cea.2021.090428.

Copyright $\bigcirc 2021$ by authors, all rights reserved. Authors agree that this article remains permanently open access under the terms of the Creative Commons Attribution License 4.0 International License

\begin{abstract}
The purposes of this study are to determine the ratio of instantaneous speed on Federal highway at Kilometer 32.9 from Kuala Lumpur to Shah Alam, to analyse the implications of the instantaneous speed ratio's numerical findings, and to examine the behaviour of convergence for each level of easiness to flow. The continuous flow model is one of the traffic flow theories that conclude the traffic flow is identical to the equation of heat. The research design used in this study is a comparative model. The continuous flow model uses a boundary value problem as well as additional constraints to solve the differential equation solution. The videotaping approach was used to select a sample of highway traffic data on the tapered acceleration path. The findings of this study disclosed that the ratio of instantaneous speed converged slower at lower levels of easiness to flow than at higher levels of easiness to flow. The ratio of instantaneous speed was found to be more accurate when the additional iteration numbers were considered and the traffic's instantaneous speed ratio on the Federal highway at Kilometer 32.9 from Kuala Lumpur to Shah Alam was less than 1.39 at location 0.4 of 1 . That value is less than 1.4 as proposed by the theoretical model. In conclusion, the mathematical model was found to be accurate in estimating the safe distance and speed of vehicles on
\end{abstract}

merging area so that the collision can be minimized and for the assessment and decision-making of the configuration of the traffic flow. As the implication, this study offers the potential to increase the efficiency of the traffic flowing through the entrance ramp.

Keywords Continuous Flow Model, Highway Operation, Instantaneous Speed Ratio, Merging Area, Partial Differential Equation, Traffic Flow

\section{Introduction}

Today, Malaysia has evolved to be a more democratic country by growing the economy and enhancing services. The population rises exponentially every year because of globalization, so this contributes to a rising number of cars in Malaysia. The construction of modern highways is therefore not only targeted at avoiding congestion, but also has different consequences on social economics, such as the ability of individuals to access schooling, jobs, and services. In the event of a disaster such as floods, landslides, pandemics, hurricanes, and tsunamis, insufficient transport networks can have devastating effects. Therefore, 
highways have a crucial link to routes for emergency services, relief, and relocation.

An entrance ramp-highway junction is typically configured to allow the driver time to estimate traffic flow and movement and to assess the necessity for speed and space before entering. However, some studies on the entrance ramp design concentrate on the development of the entrance ramp rather than evaluating the existing entrance ramp. This covers study by [1], [2], [3], [4], [5] and [6]. Therefore, it is considerable for us to widen the discussion regarding the configuration of the entrance ramp in Malaysia. It is substantial to study and reach a conclusion that is mostly about the feasibility of planning the proper design of entrance ramp, particularly in Malaysia.

This paper seeks to determine the ratio of instantaneous speed on the Federal highway at Kilometre 32.9 from Kuala Lumpur to Shah Alam. The results of this analysis would provide a deeper understanding of the macroscopic traffic flow models and suggestions for optimizing the entrance ramp's configuration. The results obtained are vital for discussion and decision about the design of the entrance ramp-highway junction. Apart from that, this paper also helps other researchers and highway planners address different challenges by making good use of existing highways and enhancing the design of the entrance ramp-highway junction.

In this study, we assess a continuous flow model, that is explained by the fact that traffic flow will be identical to the flow of viscous liquid or gas that can be compressed in one dimension. The parameter easiness to flow was used as a dependent variable by [1], that is resemble to our study. In comparison to [1], only the first iteration of the Fourier series solution was used. We agreed to limit the number of iterations in our study to a finite number. We are required to observe the convergence trend with each easiness to flow level chosen, so we practised the iterations number $n$ as a stopping measure instead of tolerance. The comparative model was used in this paper as the research design. Therefore, our findings can then be correlated with the theoretical findings reported by [1].

This study involves a selected site on Malaysia Federal Highway which is a ramp area at Kilometer 32.9 from Kuala Lumpur to Shah Alam. On the tapered acceleration lane, a sample of highway traffic data was obtained and recorded by videotaping process. The main objectives of this paper are (a) to determine the ratio of instantaneous speed on Federal highway at Kilometer 32.9 from Kuala Lumpur to Shah Alam, (b) to analyse the implications of the instantaneous speed ratio's numerical findings, and (c) to examine the behaviour of convergence for each level of easiness to flow.

\section{Literature Review}

All physical phenomenon that happens in this world can be translated into differential equations. Most problems requiring the use of numerical approaches as analytical solutions are difficult to attain. Some literatures which discussed the numerical approaches in solving differential equations are, e.g. [7] and [8]. Almost all cities and states in Malaysia are linked to highways in order to ease the congestion and travel from one destination to another city and state.

Additionally, one of the most basic standards that cities must meet is road safety. In 2019, [9] stated the effectiveness of traffic-calming interventions must be assessed not only in terms of improving street life, but also in terms of engineering and safety. In [10] specified the geometric condition of the highway, the amount of traffic flow, side barriers and intersection setting are significant in assessing the performance of the three-arm in signalized intersection of roads. There is a similar theory in this study evaluating the performance of merging area on highway.

In 2010, [11] stated that the concept methods of mathematics are an aid to understand the real-world problems. Recently, traffic simulation and traffic flow models have been prominent in the area of research. In 2013, [12] studied linear programming problems and their connections with nonlinear differential equations. In some ways, the study in [12] is linked to our analysis. Other than that, [13] analyzed the two heat transfer and Magneto hydrodynamics (MHD) flow over a permeable stretching/shrinking sheet with ohmic heating. There is almost the same principle in the studies in [12] and [13] where nonlinear partial differential equations were used and turned into ordinary differential equations.

One purpose of this paper is to examine the partial differential equation solution. The solution obtained is essential for the identification of parameters to interpret data collected in numerical results. Many mathematical models and theories of traffic flow were developed to explain the relationship between flow, speed, and density. According to [14], the knowledge of traffic stream parameters and their mutual relationships is required to get a better understanding of traffic behavior.

In 2015, [15] indicated that a merging ramp is important for vehicles to enter and exit a highway without causing any interruption on the traffic flow. The vehicles will slow down from their normal speed when they approach the merging area. In 1966, [1] stated that one of the most vital problems on traffic flow is the merging problem. It is due to the fact that the traffic condition is stochastic during the merging maneuver. This statement is supported by [16] that claimed the merging process is a complex pattern of driver behavior. The study of traffic behavior on an uninterrupted highway is significant for comfort and safety at merging maneuvers. In [17], it was indicated that the traffic congestion always occurs at the area of highway junction. This is because of the conflict between vehicles entering and exiting from the road connection as well as the vehicles passing through the main road. 


\section{Methodology}

In this paper, we want to determine the ratio of instantaneous speed on Malaysia Federal Highway i.e. on the ramp area at Kilometer 32.9 from Kuala Lumpur to Shah Alam. The iterations number of solutions are carried out to analyse the implications of the instantaneous speed ratio's numerical findings as well as to examine the behaviour of convergence for every easiness to flow level $F_{0}$. Before that, we will explain the solution of the partial differential equation by using the heat equation in general. The continuous flow model is the macroscopic model used in this study. The principle is founded on the idea of compressible fluid viscous flow in one dimension.

\subsection{Notations}

The notations which are used throughout this paper are as shown below (see e.g. [18]),

$$
\begin{aligned}
V= & \text { Vehicle speed }, \\
t= & \text { Time }, \\
N= & \text { Number of vehicles per unit time at } X, \\
Q= & \text { Amount of traffic on the highway over time } t, \\
R_{W}= & \text { Amount of ramp vehicles merging at a specific } \\
& \text { moment in time } t, \\
P= & \text { Potential for motivating pressure, } \\
X= & \text { A particular location on the highway, } \\
L= & \text { A particular segment of highway is located } \\
& \text { upstream of the merging point, } \\
\frac{V(X, t)}{\bar{V}=} & \text { The ratio of instantaneous speed at } X \\
& \text { to mean speed over a long of highway } L, \\
F_{0}= & \text { Easiness to flow, } \\
n= & \text { Iterations number }
\end{aligned}
$$

\subsection{Research Design and Approach}

The solution of the partial differential equation (1) gives a parameter that can be used to study the behavior of the traffic's instantaneous speed ratio at merging area on the Federal highway at Kilometer 32.9 from Kuala Lumpur to Shah Alam.

To formulate the model, often one refers to the general heat equation (1) as follow (see e.g. [19]).

$$
\frac{\partial^{2} P}{\partial X^{2}}-a^{2} \frac{\partial P}{\partial t}=C,
$$

where $a^{2}$ and $C$ are constant.

In developing the model, to solve the partial differential equation, the continuous flow model prescribed an initial condition as well as an array of boundary conditions. The boundary conditions aligned with the ramp are shown in Figure 1.

By referring to Figure 1, the boundary conditions which are associated with the ramp for the right-hand drive traffic can be clarified in detail. In the first situation, at $t=0$, the vehicle is unaware of the shifts in the potential for motivating pressure on the highway,

$$
P(X, 0)=P_{0} .
$$

In the second situation, at the distance $X=L$, due to the merging of traffic, the pressure potential at the entrance ramp changes from $P_{0}$ to $P_{1}$,

$$
P(L, t)=P_{1} \text {. }
$$

Lastly, for the third situation, at $X=0$, the entrance ramp in front of it has little impact on the pressure potential $P_{0}$ and the vehicle is unaffected.

$$
P(0, t)=P_{0} \text {. }
$$

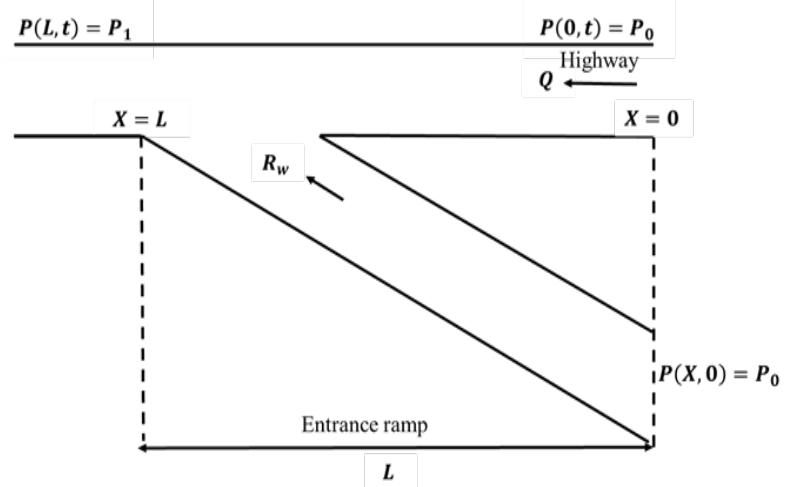

Figure 1. Highway with an entrance ramp and initial-boundary value problem (IBVP) for right-hand drive traffic.

The separation of variable technique is applied to solve the solution of the initial-boundary value problem (IBVP) in (5). However, in this paper, we do not attach specific derivation because we want to focus on the objectives of our paper. The final solution of the partial differential equation in (5) provides a parameter that can be used to determine the ratio of instantaneous speed on the Federal highway at Kilometer 32.9 from Kuala Lumpur to Shah Alam. The equation in (5) also denoted as a parameter of the instantaneous speed ratio $S_{\infty}$,

$$
\begin{aligned}
S_{\infty}= & \frac{V(X, t)}{\bar{V}}=1+\frac{R_{w}}{2 Q L}(L-2 X)+ \\
& \sum_{n}^{\infty}\left(\frac{0.2 R_{w}(-1)^{1}}{Q}-\cos \left(\left(\frac{n \pi-1}{n^{2}}\right)\right)+2(-1)^{2 n-2}\right) \\
& e^{-n^{2} F_{0}} \cos \left(\frac{n \pi X}{L}\right) .
\end{aligned}
$$




\subsection{Setting up the Iteration Number of Solution}

From equation (5), we can see that the easiness to flow parameter $F_{0}$ and instantaneous speed ratio parameter are very closely related. As mentioned, both parameters are crucial in order to achieve the objectives in this paper. The iterations number of $n$ to be examined to achieve the appropriate numerical error through the convergence values of speed ratio.

The values of $N$ are taken to be 1, 2, 3, 4 and 5 as given in equations (6)-(10), respectively. See e.g. [16].

$$
\begin{aligned}
S_{1}= & \frac{V(X, t)}{\bar{V}}=1+\frac{R_{w}}{2 Q L}(L-2 X)+\left(2-\frac{0.4 R_{w}}{Q}\right)\left(e^{-F_{i}} \cos \left(\frac{\pi X}{L}\right)\right) . \\
S_{2}= & \frac{V(X, t)}{\bar{V}}=1+\frac{R_{w}}{2 Q L}(L-2 X)+\left(2-\frac{0.4 R_{w}}{Q}\right)\left(e^{-F_{i}} \cos \left(\frac{\pi X}{L}\right)\right) \\
& +\left(2 e^{-4 F_{0}} \cos \left(\frac{2 \pi X}{L}\right)\right) . \\
S_{3}= & \frac{V(X, t)}{\bar{V}}=1+\frac{R_{w}}{2 Q L}(L-2 X)+\left(2-\frac{0.4 R_{w}}{Q}\right)\left(e^{-F_{0}} \cos \left(\frac{\pi X}{L}\right)\right) \\
& +\left(2 e^{-4 F_{0}} \cos \left(\frac{2 \pi X}{L}\right)\right)+\left(2-\frac{0.4 R_{w}}{9 Q}\right)\left(e^{-9 F_{0}} \cos \left(\frac{3 \pi X}{L}\right)\right) . \\
S_{4} & =\frac{V(X, t)}{\bar{V}}=1+\frac{R_{w}}{2 Q L}(L-2 X)+\left(2-\frac{0.4 R_{w}}{Q}\right)\left(e^{-F_{i}} \cos \left(\frac{\pi X}{L}\right)\right) \\
& +\left(2 e^{-4 F_{0}} \cos \left(\frac{2 \pi X}{L}\right)\right)+\left(2-\frac{0.4 R_{w}}{9 Q}\right)\left(e^{-9 F_{0}} \cos \left(\frac{3 \pi X}{L}\right)\right)+ \\
& \left(2 e^{-16 F_{i}} \cos \left(\frac{4 \pi X}{L}\right)\right) . \\
S_{5}= & \frac{V(X, t)}{\bar{V}}=1+\frac{R_{w}}{2 Q L}(L-2 X)+\left(2-\frac{0.4 R_{w}}{Q}\right)\left(e^{-F_{0}} \cos \left(\frac{\pi X}{L}\right)\right) \\
& +\left(2 e^{-4 F_{0}} \cos \left(\frac{2 \pi X}{L}\right)\right)+\left(2-\frac{0.4 R_{w}}{9 Q}\right)\left(e^{-9 F_{0}} \cos \left(\frac{3 \pi X}{L}\right)\right)+ \\
& \left(2 e^{-16 F_{i}} \cos \left(\frac{4 \pi X}{L}\right)\right)+\left(2-\frac{0.4 R_{w}}{25 Q}\right)\left(e^{-25 F_{0}} \cos \left(\frac{5 \pi X}{L}\right)\right) .
\end{aligned}
$$

\subsection{Data Collecting and Analysis}

The Maple programming language (Maple 2017) computes the results obtained from traffic flow data on Federal highway at Kilometer 32.9 from Kuala Lumpur to Shah Alam. The levels of easiness to flow $F_{0}$ were selected from ranging 0.1 to 5.0 based on the suggested levels by [1]. The highway traffic data were obtained by means of a videotaping method from a tapered acceleration path. All the traffic flow data were supported by the Faculty of Civil Engineering, Universiti Teknologi Mara.

\section{Results and Discussion}

\subsection{Data Collecting}

The goals of this paper are to determine the ratio of instantaneous speed on Federal highway at Kilometer 32.9 from Kuala Lumpur to Shah Alam and to analyse the implications of the instantaneous speed ratio's numerical findings. The set of data obtained on this ramp is the numerical results $S_{N}$ and errors $\left|S_{N}-S_{N-1}\right|$ of equations (6)-(10). Table 1 depicts the numerical results of $S_{N}$ and errors $\left|S_{N}-S_{N-1}\right|$ where $1 \leq N \leq 5, N \in \mathbb{N}$ for $F_{0}=0.50,0.70,1.00,3.00,5.00$. 
Table 1. Speed ratio and Errors for easiness to flow $F_{0}=0.50,0.70,1.00,3.00,500$.

\begin{tabular}{|c|c|c|c|c|}
\hline$F_{0}$ & $X / L$ & $\begin{array}{c}\text { Series solution } \\
\text { as per equation (9) } \\
S_{4}\end{array}$ & $\begin{array}{c}\text { The series solution as } \\
\text { per equation (10) } \\
S_{5}\end{array}$ & $\begin{array}{c}\text { Errors } \\
\left|S_{5}-S_{4}\right|\end{array}$ \\
\hline \multirow[t]{10}{*}{0.50} & 0.0 & $2.58 \mathrm{E}+00$ & $2.58 \mathrm{E}+00$ & $7.45 \mathrm{E}-06$ \\
\hline & 0.1 & $2.42 \mathrm{E}+00$ & $2.42 \mathrm{E}+00$ & $9.46 \mathrm{E}-07$ \\
\hline & 0.2 & $2.03 \mathrm{E}+00$ & $2.03 \mathrm{E}+00$ & $7.21 \mathrm{E}-06$ \\
\hline & 0.4 & $1.51 \mathrm{E}+00$ & $1.51 \mathrm{E}+00$ & $2.78 \mathrm{E}-06$ \\
\hline & 0.5 & $1.01 \mathrm{E}+00$ & $1.01 \mathrm{E}+00$ & $6.50 \mathrm{E}-06$ \\
\hline & 0.6 & $5.88 \mathrm{E}-01$ & $5.88 \mathrm{E}-01$ & $4.43 \mathrm{E}-06$ \\
\hline & 0.7 & $2.96 \mathrm{E}-01$ & $2.96 \mathrm{E}-01$ & $5.38 \mathrm{E}-06$ \\
\hline & 0.8 & $1.16 \mathrm{E}-01$ & $1.16 \mathrm{E}-01$ & $3.90 \mathrm{E}-09$ \\
\hline & 0.9 & $1.74 \mathrm{E}-02$ & $1.74 \mathrm{E}-02$ & $3.91 \mathrm{E}-06$ \\
\hline & 1.0 & $-3.44 \mathrm{E}-02$ & $-3.45 \mathrm{E}-02$ & $7.45 \mathrm{E}-06$ \\
\hline \multirow[t]{10}{*}{0.70} & 0.0 & $2.19 \mathrm{E}+00$ & $2.19 \mathrm{E}+00$ & $5.00 \mathrm{E}-08$ \\
\hline & 0.1 & $2.09 \mathrm{E}+00$ & $2.09 \mathrm{E}+00$ & $6.00 \mathrm{E}-09$ \\
\hline & 0.2 & $1.84 \mathrm{E}+00$ & $1.84 \mathrm{E}+00$ & 4.90E-08 \\
\hline & 0.4 & $1.49 \mathrm{E}+00$ & $1.49 \mathrm{E}+00$ & $1.80 \mathrm{E}-08$ \\
\hline & 0.5 & $1.11 \mathrm{E}+00$ & $1.11 \mathrm{E}+00$ & 4.30E-08 \\
\hline & 0.6 & $7.52 \mathrm{E}-01$ & $7.52 \mathrm{E}-01$ & 2.99E-08 \\
\hline & 0.7 & $4.64 \mathrm{E}-01$ & 4.64E-01 & $3.62 \mathrm{E}-08$ \\
\hline & 0.8 & $2.55 \mathrm{E}-01$ & $2.55 \mathrm{E}-01$ & $3.91 \mathrm{E}-08$ \\
\hline & 0.9 & $1.23 \mathrm{E}-01$ & $1.23 \mathrm{E}-01$ & $2.63 \mathrm{E}-08$ \\
\hline & 1.0 & $5.27 \mathrm{E}-02$ & $5.27 \mathrm{E}-02$ & $5.02 \mathrm{E}-08$ \\
\hline \multirow[t]{10}{*}{1.00} & 0.0 & $1.85 \mathrm{E}+00$ & $1.85 \mathrm{E}+00$ & $0.00 \mathrm{E}+00$ \\
\hline & 0.1 & $1.78 \mathrm{E}+00$ & $1.78 \mathrm{E}+00$ & $0.00 \mathrm{E}+00$ \\
\hline & 0.2 & $1.62 \mathrm{E}+00$ & $1.62 \mathrm{E}+00$ & $0.00 \mathrm{E}+00$ \\
\hline & 0.4 & $1.39 \mathrm{E}+00$ & $1.39 \mathrm{E}+00$ & $0.00 \mathrm{E}+00$ \\
\hline & 0.5 & $1.13 \mathrm{E}+00$ & $1.13 \mathrm{E}+00$ & $0.00 \mathrm{E}+00$ \\
\hline & 0.6 & $8.66 \mathrm{E}-01$ & $8.66 \mathrm{E}-01$ & $0.00 \mathrm{E}+00$ \\
\hline & 0.7 & $6.26 \mathrm{E}-01$ & $6.26 \mathrm{E}-01$ & $0.00 \mathrm{E}+00$ \\
\hline & 0.8 & 4.34E-01 & 4.34E-01 & $0.00 \mathrm{E}+00$ \\
\hline & 0.9 & $3.01 \mathrm{E}-01$ & $3.01 \mathrm{E}-01$ & $0.00 \mathrm{E}+00$ \\
\hline & 1.0 & $2.26 \mathrm{E}-01$ & $2.26 \mathrm{E}-01$ & $0.00 \mathrm{E}+00$ \\
\hline \multirow[t]{10}{*}{3.00} & 0.0 & $1.18 \mathrm{E}+00$ & $1.18 \mathrm{E}+00$ & $0.00 \mathrm{E}+00$ \\
\hline & 0.1 & $1.16 \mathrm{E}+00$ & $1.16 \mathrm{E}+00$ & $0.00 \mathrm{E}+00$ \\
\hline & 0.2 & $1.12 \mathrm{E}+00$ & $1.12 \mathrm{E}+00$ & $0.00 \mathrm{E}+00$ \\
\hline & 0.4 & $1.08 \mathrm{E}+00$ & $1.08 \mathrm{E}+00$ & $0.00 \mathrm{E}+00$ \\
\hline & 0.5 & $1.03 \mathrm{E}+00$ & $1.03 \mathrm{E}+00$ & $0.00 \mathrm{E}+00$ \\
\hline & 0.6 & $9.81 \mathrm{E}-01$ & $9.81 \mathrm{E}-01$ & $0.00 \mathrm{E}+00$ \\
\hline & 0.7 & 9.32E-01 & $9.32 \mathrm{E}-01$ & $0.00 \mathrm{E}+00$ \\
\hline & 0.8 & $8.87 \mathrm{E}-01$ & 8.87E-01 & $0.00 \mathrm{E}+00$ \\
\hline & 0.9 & $8.51 \mathrm{E}-01$ & $8.51 \mathrm{E}-01$ & $0.00 \mathrm{E}+00$ \\
\hline & 1.0 & $8.21 \mathrm{E}-01$ & $8.21 \mathrm{E}-01$ & $0.00 \mathrm{E}+00$ \\
\hline \multirow[t]{10}{*}{5.00} & 0.0 & $1.09 \mathrm{E}+00$ & $1.09 \mathrm{E}+00$ & $0.00 \mathrm{E}+00$ \\
\hline & 0.1 & $1.08 \mathrm{E}+00$ & $1.08 \mathrm{E}+00$ & $0.00 \mathrm{E}+00$ \\
\hline & 0.2 & $1.06 \mathrm{E}+00$ & $1.06 \mathrm{E}+00$ & $0.00 \mathrm{E}+00$ \\
\hline & 0.4 & $1.04 \mathrm{E}+00$ & $1.04 \mathrm{E}+00$ & $0.00 \mathrm{E}+00$ \\
\hline & 0.5 & $1.01 \mathrm{E}+00$ & $1.01 \mathrm{E}+00$ & $0.00 \mathrm{E}+00$ \\
\hline & 0.6 & $9.92 \mathrm{E}-01$ & $9.92 \mathrm{E}-01$ & $0.00 \mathrm{E}+00$ \\
\hline & 0.7 & $9.70 \mathrm{E}-01$ & $9.70 \mathrm{E}-01$ & $0.00 \mathrm{E}+00$ \\
\hline & 0.8 & $9.49 \mathrm{E}-01$ & $9.49 \mathrm{E}-01$ & $0.00 \mathrm{E}+00$ \\
\hline & 0.9 & $9.29 \mathrm{E}-01$ & $9.29 \mathrm{E}-01$ & $0.00 \mathrm{E}+00$ \\
\hline & 1.0 & $9.06 \mathrm{E}-01$ & $9.06 \mathrm{E}-01$ & $0.00 \mathrm{E}+00$ \\
\hline
\end{tabular}




\subsection{Discussion}

The numerical results of instantaneous speed ratio are generated from equations (6)-(10) by applying the traffic flow data on Malaysia Federal Highway which on-ramp area at Kilometer 32.9 from Kuala Lumpur to Shah Alam. On this ramp, the traffic volume $Q$ upon this highway is $4396 \mathrm{vph}$, the vehicles on the ramp combined one at a time $R_{w}$ is $707.689 \mathrm{vph}$ and the section's length is 185 meters. The numerical findings are helpful because it displays the speed ratio trend for this merging area. The errors $\left|S_{N}-S_{N-1}\right|$ of the instantaneous speed ratio are required in our numerical experiments for analyzing the implications of the instantaneous speed ratio's numerical findings. From the numerical results, the equations in (6)-(10) are the series with a high rate of convergence for every level of $F_{0}$ i.e. $F_{0}=0.50,0.70,1.00,3.00$ and 5.00 .

Commonly, when the numerical results obtained have been sufficiently closed with the fifth iteration $S_{5}$, tolerances are used as stopping criteria. We will not use tolerance as the stopping criterion in this paper, since we want to examine the convergence behavior for each chosen level of $F_{0}$. On the whole of the numerical results obtained, the ratio of instantaneous speed values on Federal highway at Kilometer 32.9 from Kuala Lumpur to Shah Alam can be determined based on the continuous flow model. As expected, when the additional iterations numbers are factored in, the ratio of instantaneous speed values are more reliable. In this paper, for reasonable accuracy, $N=5$ is already good enough.

We calculate the ratio of instantaneous speed with unlimited iterations, but it fails due to memory limitations on the computer. The maximum number of iterations we can complete in order to achieve the desired outcomes is $N=100000$. However, as seen in Figure 6, the ratio of instantaneous speed results is not graphically distinct when $N=5$

\subsection{Graph Plotting}

Next, we want to examine the behavior of convergence for every easiness to flow $F_{0}$ level. From Tables 1-5, we plotted the location $X / L$ as $x$-axis and instantaneous speed ratio as $y$-axis. The first iteration $S_{1}$ till fifth iteration $S_{5}$ as well as the theoretical speed ratio-distance graph are presented in Figures 2-7 as follows.

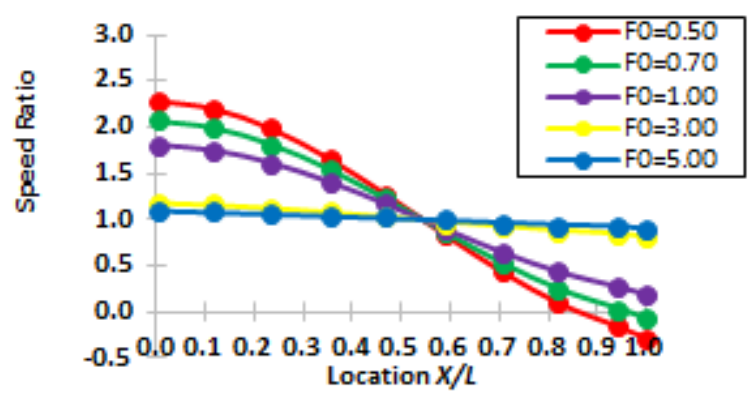

Figure 2. Speed ratio vs distance for the first iteration $S_{1}$ at $F_{0}=0.50,0.70,1.00,3.00,5.00$.

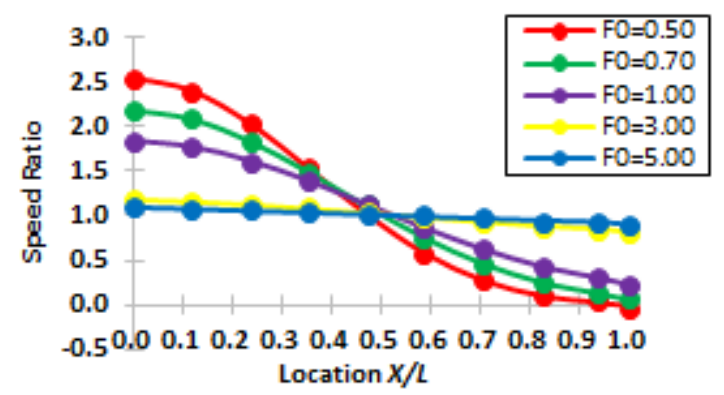

Figure 3. Speed ratio vs distance for the second iteration $S_{2}$ at $F_{0}=0.50,0.70,1.00,3.00,5.00$.

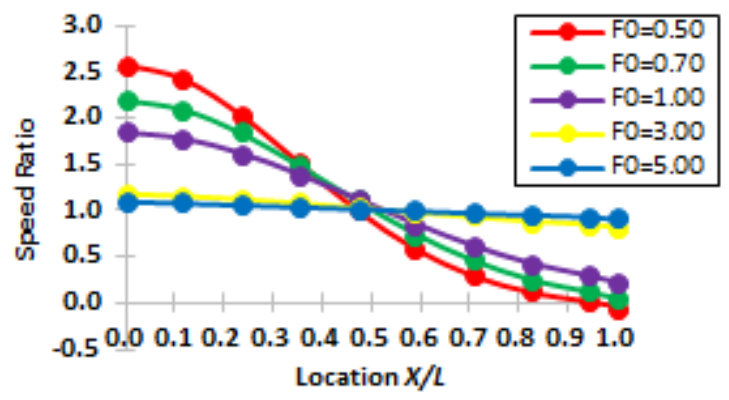

Figure 4. Speed ratio vs distance for the third iteration $S_{3}$ at $F_{0}=0.50,0.70,1.00,3.00,5.00$.

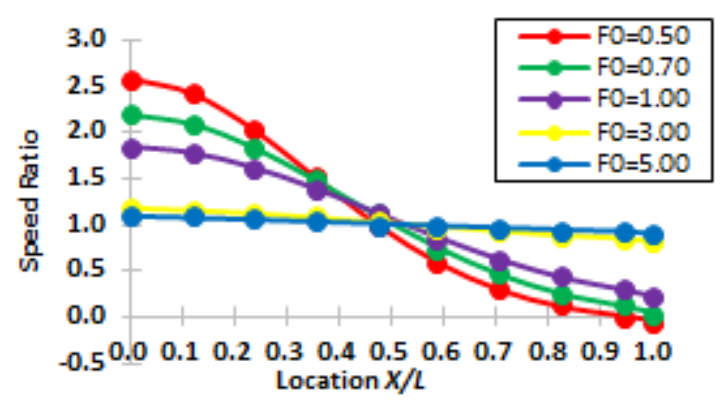

Figure 5. Speed ratio vs distance for the fourth iteration $S_{4}$ at $F_{0}=0.50,0.70,1.00,3.00,5.00$. 


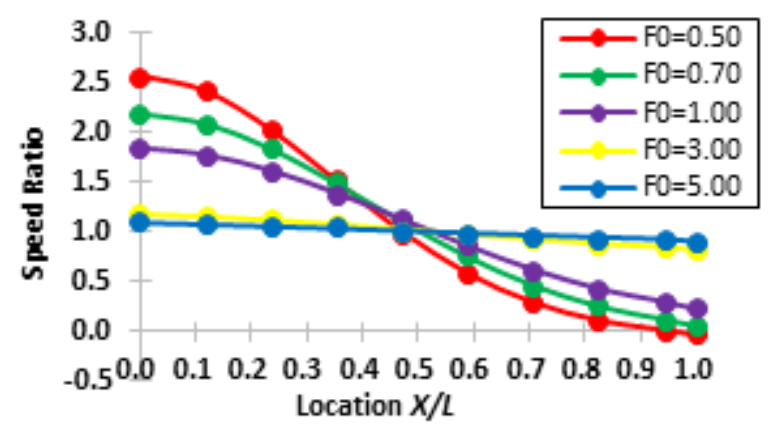

Figure 6. Speed ratio vs distance for the fifth iteration $S_{5}$ at $F_{0}=0.50,0.70,1.00,3.00,5.00$.

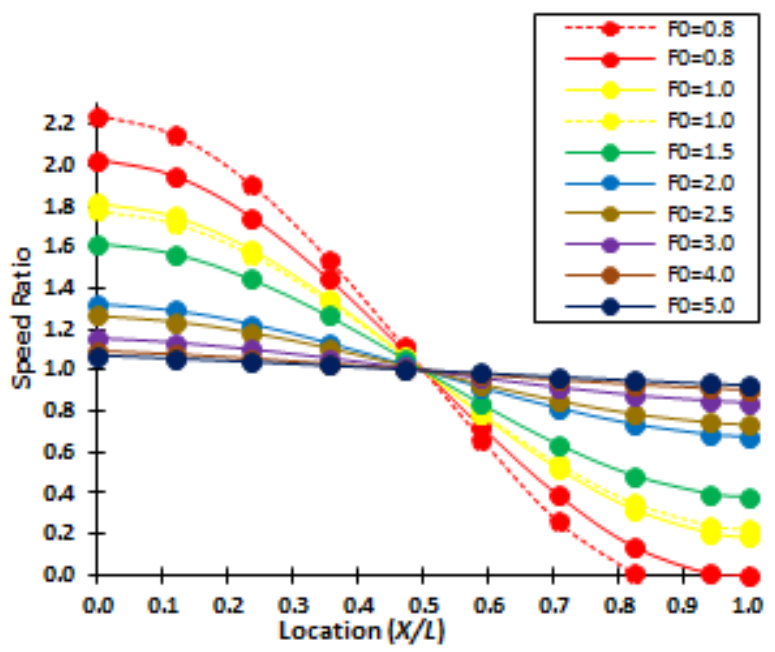

Figure 7. Speed ratio vs distance in theory. Adapted from Reddy in [1].

\subsection{Discussion}

Figure 2 shows that the speed ratio-distance graph for the first iteration $(n=1)$. The ratio of instantaneous speed values as per equation (6) is shown in dotted lines joining at the location $X / L$. From our observations, there are negative values of instantaneous speed ratio from $X / L=0.9$ meters until $X / L=1.0$ meters for $F_{0}=0.50$ and $F_{0}=0.70$. The negative values do not specify that the vehicles are heading backward or in the wrong direction. In Figures 3-5, we can see that all the lines of easiness to flow $F_{0}$ levels intersect at approximately in the middle of the graph at $L / 2=92.5$ meters. If we compare Figure 3 to Figure 5, certain significant variations are apparent. Figure 6 shows the instantaneous speed ratio-distance graph for the fifth iteration $(n=5)$. As we can see the graph in Figure 6 provides the predicted graph as seen in Figure 7.

Based on Figure 6, at the higher levels of $F_{0}$ i.e. $F_{0}=1.00,3.00$ and 5.00 , they appear to converge faster and have stable value at almost 1 . This is because the vehicles are driving slowly due to intense traffic. However, Figure 6 reveals that if we add the number of iterations $n$ to 5 then the ratio of instantaneous speed does not show much difference after $N$ is equal to 5 . We also can see the errors $\left|S_{5}-S_{4}\right|$ are inclined to 0 (see Table 1). At lower levels of $F_{0}$ i.e. $F_{0}=0.50$ and 0.70 , Figure 6 displayed that the ratio of instantaneous speed values converges more slowly to the desired solution. Besides, at lower levels of $F_{0}$ i.e. $F_{0}=0.50$ and 0.70 , the vehicles are not moving at uniform speed along the location $(X / L)$ of highway. It is attributed to the drivers having at least $1 / 5$ of $L / 2$ to slow down their cars to prevent a collision.

In this paper, $X / L=0.4$ is obtained from $1 / 5$ of $L / 2$ from the starting point of location $(X / L)$. Figure 6 shows that the detailed graph on the Federal highway at Kilometer 32.9 from Kuala Lumpur to Shah Alam achieves the specification to minimize the collision. The ratio of instantaneous speed is observed to be below 1.39 $(\leq 1.39)$ for the higher levels of $F_{0}$ i.e. $F_{0}=1.00,3.00$ and 5.00 at $X / L=0.4$ (see Table 2).

Table 2. The ratio of instantaneous speed when $X / L=0.4$ for every easiness to flow $F_{0}$.

\begin{tabular}{cccccc}
\hline$F_{0}$ & \multicolumn{5}{c}{ Instantaneous Speed Ratio } \\
& $S_{1}$ & $S_{2}$ & $S_{3}$ & $S_{4}$ & $S_{5}$ \\
\hline 0.50 & 1.66 & 1.54 & 1.52 & 1.51 & 1.51 \\
0.70 & 1.54 & 1.49 & 1.49 & 1.49 & 1.49 \\
1.00 & 1.39 & 1.39 & 1.39 & 1.39 & 1.39 \\
3.00 & 1.08 & 1.08 & 1.08 & 1.08 & 1.08 \\
5.00 & 1.04 & 1.04 & 1.04 & 1.04 & 1.04 \\
\hline
\end{tabular}

Figure 7 shows the theoretical speed ratio -distance graph. The particular location $(X / L)$ along the highway is varied in increments of 20 meters. We found a few similarities in comparing the graphs in Figure 6 to Figure 7. In Figure 6 and Figure 7, we observe that the ratio of instantaneous speed approaches unity whenever the levels of $F_{0}$ get higher or close to 5.00. Other than that, as the levels of easiness to flow $F_{0}$ increase, the ratio of instantaneous speed decreases in the portion of the highway from 0 to $L / 2=0.5$ and continuously decreases from $L / 2=0.5$ to $L=1.0$. The ratio of instantaneous speed at location 0.4 is less than 1.4 , according to the conceptual graph in Figure 7. Based on Figure 6 and Table 2 , the ratio of instantaneous speed is less than 1.39 at $X / L=0.4$. It can be deduced that the ramp area on the Federal highway at Kilometer 32.9 from Kuala Lumpur to Shah Alam is good and achieves the criteria in reducing the collision.

\section{Conclusion}

This study focused on the idea of compressible fluid 
viscous flow in one dimension. This theory defines the movement of traffic as similar to the movement of fluid or gas. We resolved the continuous flow model for the traffic of the right-hand drive. In the continuous flow model, the pressure potential principle offers a strong theoretical basis to describe the variation of the speed ratio on the merging area. In order to determine the ratio of instantaneous speed, the easiness to flow is used as a dependent variable.

Overall, the ratio of instantaneous speed displays slower convergence at lower levels of $F_{0}$ i.e. when $F_{0}=0.50$ and 0.70 . But, the ratio of instantaneous speed shows a faster convergence at higher levels of $F_{0}$ i.e. $F_{0}=1.00,3.00$ and 5.00 . We concluded that the traffic's instantaneous speed ratio on the selected area is sufficient to avoid traffic accidents. It is proven by the obtained value of the ratio of instantaneous speed i.e. less than 1.39 at the location $X / L=0.4$. This value agrees with the value as proposed by the theoretical model i.e. less than 1.4 .

The results of this study include a deeper interpretation of both the continuous flow model and the approaches used to enhance the design of the entrance ramp. The findings obtained are essential for the assessment and decision-making of the configuration of the traffic flow.

For the recommendation of future studies, we suggest to study a new parameter other than instantaneous speed ratio and easiness to flow that we can measure in evaluating the car theories and models. Other than that, we recommend the study of the theory that relates with the reasonable range level of easiness to flow. Furthermore, it is also suggested to calculate the instantaneous speed ratio for different other locations of ramp area in order to make conclusion on the efficiency of ramp design. Lastly, it is suggested to further the studies to explore the stochastic flow model that may give the desired results through a statistical approach.

\section{Acknowledgment}

The authors would like to thank Ministry of Higher Education in Malaysia for funding through Fundamental Research Grant Scheme (FRGS) (code no: 2019 - 0010 107 - 02) (FRGS / 1 / 2018 / STG06 / UPSI / 02 / 4).

\section{REFERENCES}

[1] Reddy, M.S. (1966). Quantitative Evaluation of the Effect of Merging Vehicles on Freeway Operation. PhD. Thesis. Texas $A$ and $M$ University.

[2] Adnan, M. A. (2007). Development of Entrance Ramp Merging Density Model Based on an Urban Expressway Traffic Condition.PhD.Thesis. Universiti Sains Malaysia, Malaysia
[3] Shin, H. S., Lee, Y. J., Dadvar, S., \& Bharti, S. (2016). The Development of Local Calibration Factors-Phase II: Maryland Freeways and Ramps.

[4] Wang, T., Wang, C., \& Qian, Z. (2017). Development of a New Conflict-Based Safety Metric for Freeway Exit Ramps. Advances in Mechanical Engineering, 9(9).

[5] Choi, Y. H., Park, S. H., Ko, H., Kim, K. H., \& Yun, I. (2018). Development of Safety Performance Functions and Crash Modification Factors for Expressway Ramps. KSCE Journal of Civil Engineering, 22(2), 804-812.

[6] Slaug, B., Jonsson, O., \& Carlsson, G. (2019). Public entrance accessibility: Psychometric Approach to the Development of a New Assessment Instrument. Disability and Health Journal, 12(3), 473-480.

[7] Mohamed, N.A, Ibrahim, N.F, Yusof M.R.M, Mohamed, N.F, \& Mohamed, N.H. (2016a). Implementation of Boundary-Domain IntegroDifferential Equation for Dirichlet BVP with Variable Coefficient. Journal Teknologi, 78(65), 71-77.

[8] Mohamed, N.A, Mohamed, N.F, Mohamed, N.H. \& Yusof M.R.M. (2016b). Numerical Solution of Dirichlet BoundaryDomain Integro-Differential Equation with Less Number of Collocation Points. Applied Mathematical Sciences, 10(50), 2459-2469.

[9] Natalia Distefano, Salvatore Leonardi (2019). Evaluation of the Benefits of Traffic Calming on Vehicle Speed Reduction. Civil Engineering and Architecture, 7(4), 200 - 214. DOI: 10.13189/cea.2019.070403

[10] Asep Setiawan (2019). Evaluation of Performance Non-signal Intersection on Telekomunikasi Road Intersection - Terusan Buah Batu Road, Bandung - West Java. Civil Engineering and Architecture, 7(3A), 77 - 85. DOI: 10.13189/cea.2019.071311

[11] Abdul Aziz, Z. (2010). An Overview of the Importance of Industrial Mathematics. Journal of Science and Mathematics Letters, 2(2), 9-17.

[12] Wan Zaimi, W. M. K. A., Abu, M. S., Junoh, A. K., Ariffin, W. N. M., \& Shukeri, S. N. (2013). Model Pengaturcaraan Linear untuk Meminimumkan Masa Menunggu Lebihan Penumpang Feri ke Pulau Langkawi. Journal of Science and Mathematics Letters, 1, 35-46

[13] Md Ali, Z., Jamaruddin, N., Soid, S. K., Mohd Idris, N. A., Udin, M. N., \& Ismail, N. Z. (2019). Unsteady MHD Flow and Heat Transfer Over a Stretching/Shrinking Permeable Sheet with Ohmic Heating. EDUCATUM Journal of Science, Mathematics and Technology, 6(2), 55-61.

[14] Haque, N. N., Halder, S., Islam, M. A., Nag, R., Alam, M. R. B., Hassan, M. M., \& Hasnaine M. S. (2013).Traffic Speed Study. Department of Civil Engineering. Ahsanullah University of Science and Technology.

[15] Sun, J., Li, Z., \& Sun, J. (2015). Study on Traffic Characteristics for a Typical Expressway on Ramp Bottleneck Considering Various Merging Behaviors. Physics A: Statistical Mechanics and its Applications, 440, 57-67.

[16] Gettman, D., Head, L., \& Mirchandani, P. (1999). RHODES-ITMS Corridor Control Project.

[17] Kwon, S., \& Kim, T. (2018). Study on the Behavior of 
Merging Vehicles at Highway Junctions. Journal Information Service System, 179-179.

[18] Husin Basri, N.S, Mohamed, N.A, Adnan, M.A, Mohamed, N.F, \& Zainuddin, N.H. (2020). Instantaneous Speed Ratio of Traffic Flowing through a Merging Area at Kilometer 31.6 on the Highway from Shah Alam to Kuala Lumpur. Pertanika J.Sci. \& Technol., 28(2), 565-578.

[19] Widder, D. V. (1976). The heat equation. Academic Press, 67. 